\section{Max Klein}

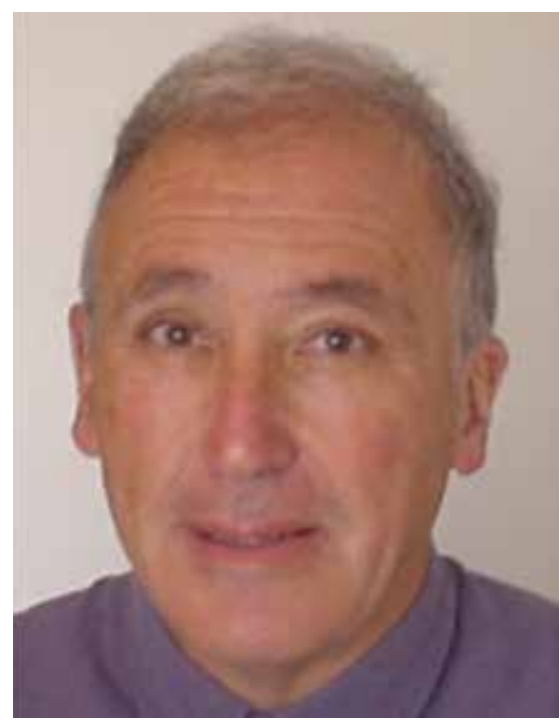

Max Klein died unexpectedly on 27 January 2015 while riding his bicycle with friends near Stellenbosch.

Max grew up in the country districts, and came to Cape Town as a schoolboy at South African College Schools (SACS). He went to medical school at the University of Cape Town, where his experience included a bout of meningococcal meningitis, which profoundly affected his view of patient care.

Early in his medical career he was a Wellcome Research Fellow in the neonatal intensive care unit (ICU) at Groote Schuur Hospital. Together with Vincent Harrison, Boet Heese and Atties Malan, he was involved in early research on neonatal ventilation, and was part of a remarkable study elucidating the significance of grunting in newborn infants with hyaline membrane disease. ${ }^{[1]}$ Vincent Harrison has written of the remarkable originality of thought that Max displayed during this time and throughout his career.

Subsequently, he trained in paediatrics at the Red Cross War Memorial Children's Hospital (RCWMCH), before going on to train in respiratory medicine with Attie de Kock at Stellenbosch University (Karl Bremer Hospital). In 1972, he went to the Cardiovascular Research Unit and the Department of Paediatrics at the University of California Medical Centre in San Francisco, USA, on a Lilly International Fellowship, before returning in 1974 to RCWMCH as head of the paediatric ICU and respiratory service. He remained in that role until stepping down as head of the paediatric ICU in 1999.

Max played a significant role in the development of paediatric intensive care in South Africa (SA) and beyond. Many senior paediatric intensivists across the world received their exposure to paediatric intensive care under his tuition. Something of his role in paediatric critical care was recognised when he was presented with the gold medal of the World Federation of Pediatric Intensive and Critical Care Societies in 2000 in Montreal. He was also awarded the President's Award of the Critical Care Society of Southern Africa in recognition of his noteworthy contribution to paediatric (and adult) intensive care in SA. He was a remarkable clinical physiologist, with unique insight into a variety of conditions including croup (for which he developed a scoring system that has been used extensively in SA), oropharyngeal obstruction (for which he developed the system of continuous insufflation of the pharynx), respiratory failure (for which he developed innovative approaches to ventilation), shock (with a clear and lucid approach to diagnosis and management of hypovolaemia), among many other conditions. There are many children who benefitted from his clear insight and innovative thought, while many clinicians were deeply affected by his attention to detail, clinical acumen and understanding of pathophysiological processes. Perhaps most importantly, he cared deeply for the welfare of his patients and was not prepared to comply with dicriminatory practices.

Under his leadership, the tracheostomy and home ventilation service at the RCWMCH developed into a remarkably successful prototype of effective home care of children with complex conditions.

He played a significant role in the development of the Critical Care Society of Southern Africa: organising conferences and delivering presentations; participating in council and annual general meetings; and joining in with gusto at celebrations and parties. He played a similar role within the pulmonology community.

After his retirement from intensive care, Max continued to head the Department of Paediatric's pulmonology unit at RCWMCH until his retirement. Thereafter he continued to teach and consult in paediatric respiratory medicine across the country. He was appointed as the first Extraordinary Professor in the Department of Paediatrics and Child Health at the University of Pretoria.

Max was not always easy to get on with, and he disagreed vehemently with quite a few people. But he will be remembered for his clinical skills, his commitment to patient and family care and for his remarkable contributions as a teacher and innovator in paediatric critical care and pulmonology.

Reference

1. Harrison VC, Heese $H$ de V, Klein M. The significance of grunting in hyaline membrane disease. Pediatrics 1968;41(3):549-559.

\section{A C Argent}

Department of Paediatrics and Child Health, University of Cape Town and Paediatric Intensive Care Unit, Red Cross War Memorial Children's Hospital, Cape Town, South Africa 